\title{
Stigma, imipramine and inequity in health
}

\section{Vajira Dharmawardene}

Shanika is a 45 year old mother of two children and a lawyer by profession. She is a well-known person in her area, partly due to her job and also due to her being a daughter of a prominent businessman in the country. She was diagnosed to have panic disorder after years of being treated for having a physical illness. After being on cocktails of psychotropic drugs she achieved almost complete remission of her symptoms thanks to an "astonishingly cheap drug" called imipramine. She had received all her care in private sector all the years and could not believe that all her misery could be solved by a drug that cost mere rupees 250 per month as she had spent thousands of rupees for multiple treatments she had been on.

Three months ago when she went to the usual pharmacy to get her monthly supply of imipramine, pharmacist had told her that the drug was not available. On hearing this news, she almost experienced a panic attack and frantically went looking for the drug in other nearby pharmacies, including government's "Osusala", only to be told the drug is not available and out of stock with the "company", meaning the supplier, as well. Her husband initiated a countrywide search operation and found tablets sufficient for about two months. When she called the government's medicine helpline she was told that the drug is available in government hospitals and she should visit the same to get her supply. Shanika could not make up her mind to go to a government psychiatric clinic as she feared she could be labeled as mad. Now she gets her treatment from the hospital clinic through a second person who visits the hospital on her behalf, after an arrangement she made with her treating Psychiatrist.

The story of Shanika tells rarely described facets of health care system of Sri Lanka.

Firstly, it indicates that being wealthy may not ensure that one receives the best treatment or access to the treatment one wishes for. There is some evidence that wealthy may actually receive inappropriate and expensive treatment. ${ }^{1}$ Secondly, it tells about an inequity of a special kind. Health inequity or disparity is usually defined as unjust differences in health between the individuals of different social groups that can be linked to various disadvantages. Place of residence, gender, age, race, religion are some of the disadvantages identified. ${ }^{2}$ By far the most commonly studied and described inequity is due to low socio economic status. Peculiarly in this instance, a person of relatively higher socio-economic status was at risk of losing her wellbeing due to poor access to probably the cheapest antidepressant medication in the country.

Imipramine is one of the three essential antidepressants in Sri Lanka essential drug list ${ }^{3}$ and one of the most commonly prescribed antidepressant in the country due to wide availability in government hospitals, long experience with the drug and due to unique responsiveness shown by some individuals with mood and anxiety disorders to this medication. It could be safely used in pregnancy 
and childhood as well, devoid of risks discussed in association with selective serotonin reuptake inhibitors.

It is the drug that established the monoamine theory of depressive disorder ${ }^{4}$ and field of pharmacotherapy for panic disorder. ${ }^{5}$ Despite several newer agents being more commonly available and prescribed, ${ }^{6}$ imipramine remains an efficacious agent for treatment of panic disorder and depressive illness.

Thirdly, it shows that the country's health care system has failed to ensure that an essential drug like imipramine is not widely available for the needy clients. A drug being cheap could make it less attractive for the private sector, though profit should not be the criterion when making pharmaceuticals available. The state has a responsibility to make sure appropriate access to medical care is equally available to all patients, both in private and public sector. The cheap but effective essential pharmaceuticals should be consistently available at least in government "Osusala" outlets as close to $50 \%$ of the country's health expenditure is borne out of pocket by public. ${ }^{7}$

Fourthly this could be considered as yet another example of failure of the market economy model in providing comprehensive and evidence-based health care for the people.

Finally the fact that she was not willing to visit the government hospital's psychiatric service indicates that her confidentiality could not be ensured in the way mental health services are provided in Sri Lanka.

Story of Shanika highlights the less discussed stigma around mental illness that make present hospital based mental health care that is unattractive to people unless they are in an emergency situation that needs admission to an inpatient care unit. The poor probably has no choice but receive whatever the service is available to them, disregarding the stigma. Fear of labeling, lack of confidentiality and social judgment are recurrent subthemes associated with mental health related stigma. ${ }^{8}$ Freedom from stigma could be a non affordable luxury for the poor. Or they could be contributing to the treatment gap, the unknown dark matter in mental health.

Sri Lanka needs to graduate from hyping the glory of great public health milestones to confront the other indicators of good health care that will ensure that equity in health care is attained for all.

\section{References:}

1. Brownlee S, Chalkidou K, Doust J, et al. Evidence of overuse of medical services around the world. Lancet 2017; 390: 156-168

2. Arcaya MC, Arcaya AL, Subramanian SV. Inequalities in health: definitions, concepts, and theories. Glob Health Action. 2015;8:27106. Published 2015 Jun 24.

3. Ministry of Health Care and Nutrition Sri Lanka and Department of Pharmacology, Faculty of Medicine University of Colombo Report of the expert committee on essential medicines, 2009. 4th revision http://www.who.int/selection medicines/country lists/lka eml 2009.pdf (accessed on Nov 10 2019)

4. López-Muñoz F, Alamo C, Monoaminergic neurotransmission: the history of the discovery of antidepressants from 1950s until today. Curr Pharm Des. 2009;15(14):1563-86 
5. Klein DF: Delineation of two drug-responsive anxiety syndromes. Psychopharmacologia 5:397408,1964

6. Dharmawardene $\mathrm{V}$, Menkes DB. Psychotropic drugs in low-income countries. The Lancet Psychiatry. 2014;17:490-2.

7. Amarasinghe S, De Alwis S, Saleem S et al.IHP Technical Reports Series, Number 2: Private Health Sector Review 2012 (Revised edition) Colombo Institute for Health Policy. August 2015

8. Clement S, Schauman O, Graham T, Maggioni et al. (2015). What is the impact of mental healthrelated stigma on help-seeking? A systematic review of quantitative and qualitative studies. Psychological Medicine, 45(1), 11-27. 